\title{
Development and validation of tools for the implementation of european air quality policy in Germany (Project VALIUM)
}

\author{
M. Schatzmann ${ }^{1}$, W. Bächlin ${ }^{2}$, S. Emeis ${ }^{3}$, J. Kühlwein ${ }^{4}$, B. Leitl ${ }^{1}$, W. J. Müller ${ }^{5}$, K. Schäfer ${ }^{3}$, and H. Schlünzen ${ }^{1}$ \\ ${ }^{1}$ Meteorological Institute, ZMAW, University of Hamburg, Germany \\ ${ }^{2}$ Ingenieurbüro Lohmeyer GmbH \& Co. KG, Karlsruhe, Germany \\ ${ }^{3}$ Forschungszentrum Karlsruhe, IMK-IFU, Garmisch-Partenkirchen, Germany \\ ${ }^{4}$ Institute of Energy Economics and the Rational Use of Energy, University of Stuttgart, Germany \\ ${ }^{5}$ Lower Saxony State Agency for Ecology, Hannover, Germany
}

Received: 15 August 2005 - Published in Atmos. Chem. Phys. Discuss.: 5 October 2005

Revised: 16 June 2006 - Accepted: 22 June 2006 - Published: 24 July 2006

\begin{abstract}
In the framework of the German Atmospheric Research Program AFO-2000 a system of consistent coupled numerical models has been developed. The purpose of the model system is to serve as a tool for the execution of European urban air quality regulations. A consortium with the acronym VALIUM was formed, which consisted of German research institutes, environmental consultancies and an environmental agency.

A substantial part of the VALIUM program was devoted to the generation of a set of high quality data for the validation of the numerical model system. The validation data are based on a combination of field studies, tracer experiments and corresponding wind tunnel experiments. The field experiments were carried out inside and around a street canyon in a city district of Hanover/Germany. After a brief introduction to the VALIUM project a summary of the main results will be given.
\end{abstract}

\section{Introduction}

This paper provides a short and selective review of project VALIUM which aimed on the development and validation of tools as they are needed for the execution of the European Air Quality Guideline 96/62/EU and its daughter directives. This set of regulations requires from the EU member states to submit maps that show the spatial distribution of air pollutants

Correspondence to: M. Schatzmann

(schatzmann@zmaw.de)
- for the member state in total,

- for conurbations with more than 250000 inhabitants and

- for micro environments as, e.g., city districts subject to high pollutant concentrations.

Project VALIUM comprised the following tasks:

- Development of the numerical model system M-SYS which is capable to provide pollutant concentrations in spatial resolutions matched to the regional and local scales,

- development of a methodology to generate emission data with resolutions as required by the models,

- generation of a high quality data set based on a combination of field measurements and wind tunnel simulations in a city district, and finally

- presentation of the measured data in the form of a generally accessible data base and utilization of the data for the validation of M-SYS and its parameterisations.

Project VALIUM was designed as the German core project for EUROTRAC-SATURN "Studying Atmospheric Pollution in Urban Areas" (Moussiopoulos, 2003).

\section{Experiments}

The field measurements were made at the test site "Goettinger Strasse" in Hanover/Germany (Fig. 1). This side includes a busy street canyon with approximately 30000 vehicles per day, a large percentage of them being trucks. Since

Published by Copernicus GmbH on behalf of the European Geosciences Union. 


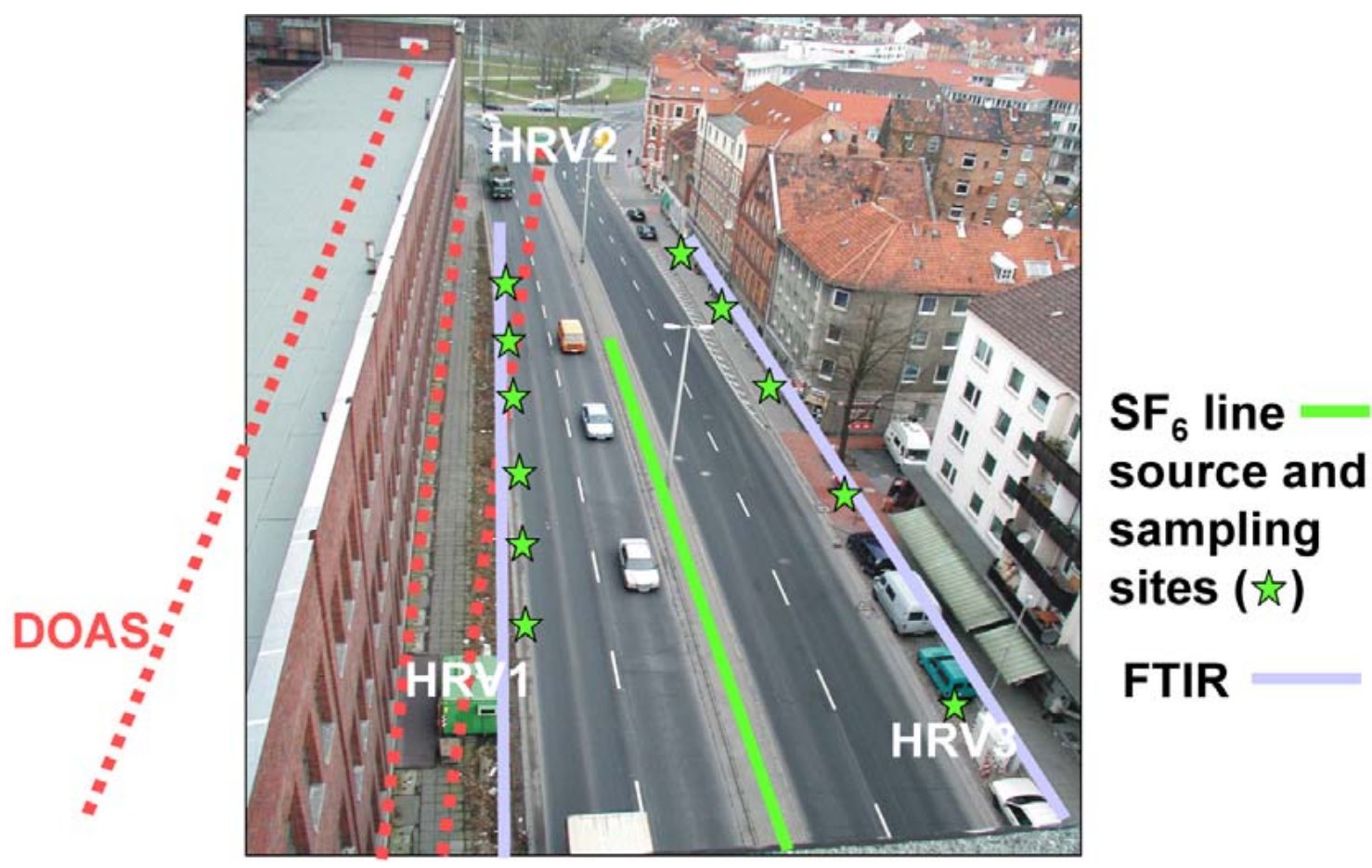

Fig. 1. Street Canyon "Goettinger Strasse" with instrumentation. The picture shows the continuous monitoring stations HRV1 to HRV3 and the SF6-line-source at the median strip plus the sampling bag locations (solid line). The path-averaged measurements are indicated by the dotted lines.

nearly two decades the Lower Saxony State Agency for Ecology (NLÖ) operates a monitoring station at this site. Long time series of data are available which offer the opportunity to approach the urban air pollution problem also by statistical methods (Schatzmann and Leitl, 2002).

Continuous measurements of air pollutants inside the street canyon and in an area of $1 \mathrm{~km} \times 1 \mathrm{~km}$ surrounding the canyon were performed in addition to the routine NLÖ monitoring from early 2001 until the end of 2003. Both air pollutants and meteorological parameters were measured by insitu instruments at four locations inside the street canyon and at three locations in the surroundings of the canyon (one of those being a roof-top station at the highest building in that area). Path-averaging optical measurement techniques (two, some times three DOAS systems) were used continuously at the ground and at building roof level. The meteorological background (vertical profiles of wind and turbulence plus mixing layer height) came from a SODAR system that was positioned about $500 \mathrm{~m}$ apart from the street canyon (Emeis, 2004; Emeis and Türk, 2004). The determination of the mixing layer height over an urban area is a subject of ongoing research (Baklanov et al., 2006 ${ }^{1}$; Rotach et al., 2005).

\footnotetext{
${ }^{1}$ Baklanov, A., Joffre, S., Piringer, M., Deserti, M., Middleton, D., Tombrou, M., Karppinen, A., Emeis, S., Prior, V., and Rotach, M.: Towards Estimating the Mixing Height in Urban Areas - Recent Experimental and Modelling Results from the COST-715 Action, Bound.-Lay. Meteorol., submitted, 2006.
}

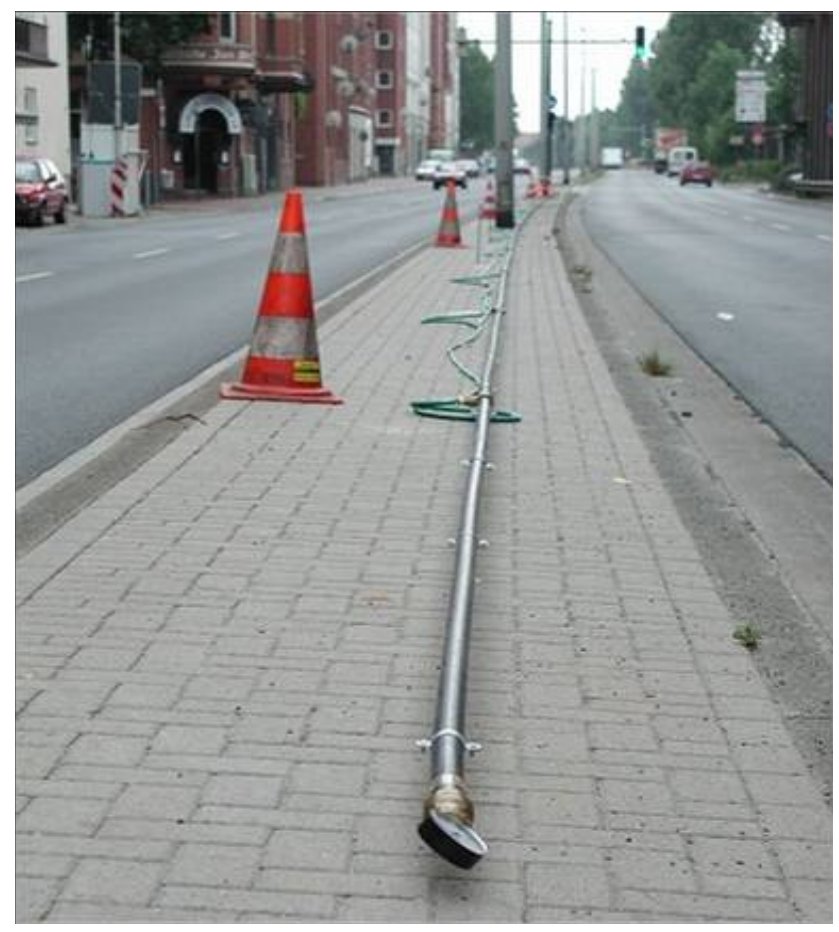

Fig. 2. Picture of the $96 \mathrm{~m}$ long SF6 line source which was positioned on the median strip of the street canyon. 
Three intensive observation periods (IOPs) in different seasons were successfully executed. Path-averaged concentrations of air pollutants were measured at both sides of the street using FTIR spectrometry. In addition, vertical gradients of air pollutants in the street canyon were determined applying a DOAS-system. During selected periods, the standard meteorological measurements performed continuously at the roof top station and by the SODAR system were complemented by those of (1) a ceilometer (operated by Vaisala, Münkel et al., 2004) that was located at the roof of a building, and (2) a Wind-Temperature-RADAR (WTR, operated by IMK-ASF). The ceilometer (aerosol backscatter profile, Schäfer et al., 2004) and WTR mixing layer height data (temperature profile) were used for comparisons with the SODAR data (Emeis et al., 2004). All measurement systems were carefully calibrated. Simultaneous operation of the different instruments carried out at one site before or after each IOP showed only differences in the order of the specified accuracy of the instruments.

Most of the previous field experiments carried out in urban areas suffer from the fact that the source term is not properly known. There is the choice between several emission models that link the traffic flow to the source strength. Since the concentration fields predicted in dispersion calculations are directly proportional to the source strength, the results of numerical models may to a large degree depend on the particular choice of the emission model. In order to circumvent this problem, the meteorological and pollutant measurements in the Goettinger Strasse were complemented by some tracer experiments. An artificial line source was installed on the median strip dividing the four traffic lanes, and controlled amounts of $\mathrm{SF}_{6}$ were released (Fig. 2). The line source had a length of $96 \mathrm{~m}$. Air probes were collected at 15 sampling points within the street canyon and at roof level. The $\mathrm{SF}_{6}$ content of the probes was subsequently analysed in the laboratory. For altogether 8 days within the period 2001 to 2003,100 half-hourly averaged concentration values were determined at each monitoring position. Additionally path averaged concentrations of tracer $\mathrm{SF}_{6}$ were measured at both sides of the street using FTIR spectrometry. Prevailing wind directions during the experiments were westerly for five days and northerly, easterly and southerly, respectively, for the remaining 3 days.

The tracer experiments provided the opportunity to validate not only dispersion models but emission models as well. During the intensive observation periods, manual traffic counts were carried out together with traffic speed measurements (Fig. 3). In addition, the vehicles were subject to an automated plate number registration. The subsequent consultation of the German vehicle register allowed the exact determination of the vehicle engines and, by means of emission factors, the best possible quantification of the traffic emission rate.

The weather conditions during field campaigns cannot be controlled, one has to cope with the weather as it is.
The boundary conditions for the experiments are only partly known and, even worse, they change continuously due to the diurnal cycle. Therefore, VALIUM comprised also a wind tunnel sub-project that was tasked to support the field measurement campaigns with corresponding flow visualization experiments and with some systematic sensitivity studies which help to analyse and to understand the data. In addition complete fields of velocity and concentration were measured within the street canyon with a spatial resolution which corresponds to that of micro-scale numerical models. A detailed aerodynamic wind tunnel model of the urban site was built, the complete model covering an area of about $1 \mathrm{~km} \times 1 \mathrm{~km}$. A wind tunnel boundary layer corresponding to the model scale $(1: 250)$ was generated utilizing a combination of vortex generators and floor roughness elements. The complete mean and turbulent boundary layer properties were determined. Subsequently numerous and until now unique experiments have been carried out from which only a few examples can be presented in the results part of this paper.

\section{Numerical model development}

The meso- and micro-scale meteorological and chemistry transport models METRAS (Schlünzen, 1990), MITRAS (Schlünzen et al., 2003), MECTM (Lenz et al., 2000) and MICTM (Grawe, 2006 ${ }^{2}$ ) were combined to the model system M-SYS (Trukenmüller et al., 2004). Three mesoscale and one micro-scale model area were used to receive concentration maps of different resolution. For M-SYS the necessary input data (building inventory, emission inventory) has been processed, and an analysis procedure on the basis of routine meteorological observations was developed. The gas phase chemical mechanism was complemented with simple aerosol chemistry, and a nudging method for chemical data assimilation was implemented and applied. The sensitivity of model results on the different horizontal resolutions used in the mesoscale was reduced by calculating aggregated surface fluxes for the meteorological parameters (Schlünzen and Katzfey, 2003). All these measures lead to a significant improvement of model performance in comparison with observations. After completion of the development phase a large number of simulations were made.

\section{Results}

The VALIUM experiments are up to now the probably worldwide largest and most detailed of its kind. In order to make the data generally accessible, the "intelligent" database VALIDATA was created that comprises the measurements in a

\footnotetext{
${ }^{2}$ Grawe, D.: Verknüpfung von Modellen und Messungen zur Konzentrationsvorhersage, PhD-thesis, Fachbereich Geowissenschaften, University of Hamburg (in German), in preparation, 2006.
} 


\section{Traffic Counts and Velocity Measurements with Laser Instruments, Vehicle Categorisation (Trucks, Passenger Cars ...)}

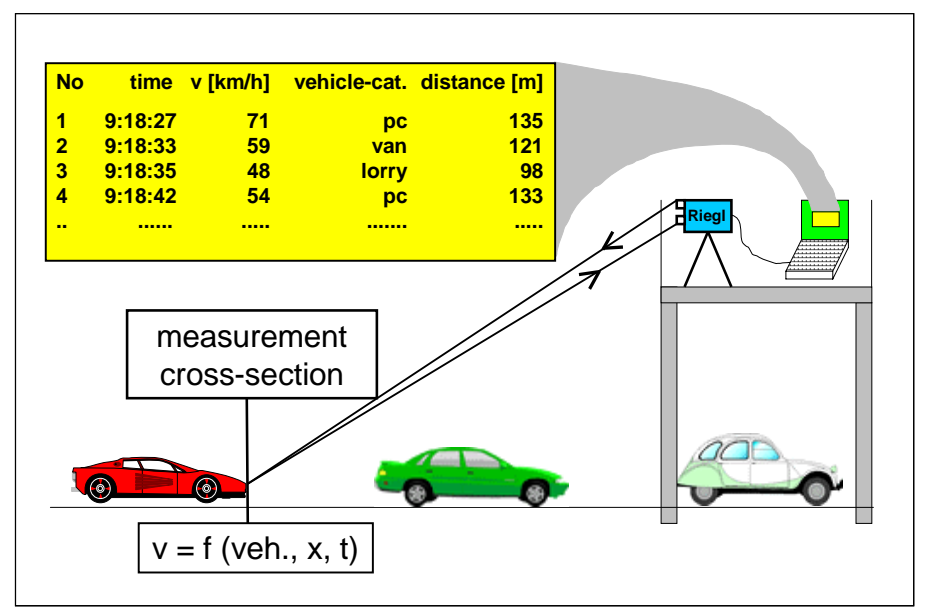

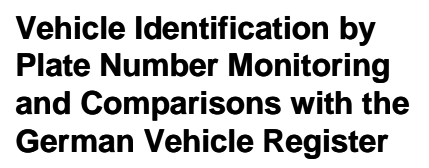

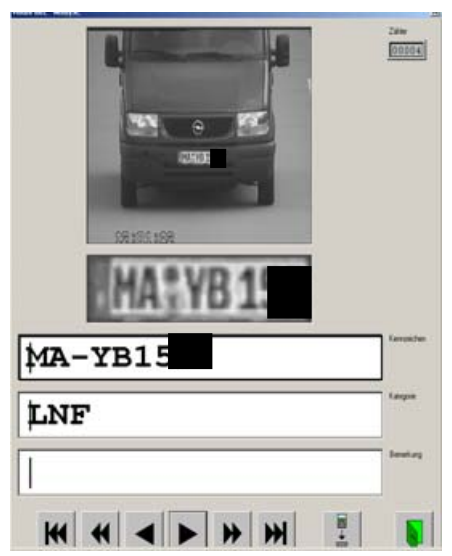

Fig. 3. Experimental set-up for traffic counts and vehicle speed measurements.

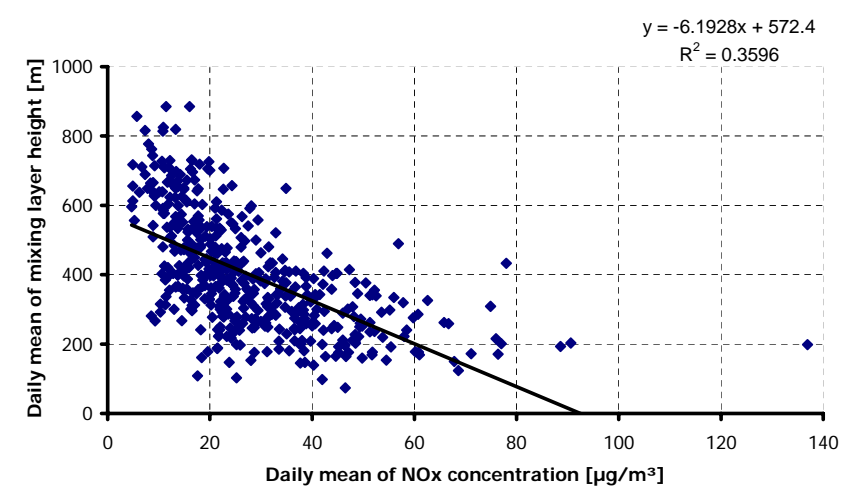

Fig. 4. Correlation of $\mathrm{NO}_{\mathrm{x}}$ with mixing layer height for the roof-top station at Goettinger Strasse.

well-documented and easily understandable form. Before the data entered the database they have been checked for plausibility and consistency. Part of the examination was the comparison of the spot concentrations at the monitoring positions with the line-averaged measurements along the Goettinger Strasse. Furthermore the dilution of the tracer gas $\mathrm{SF}_{6}$ was compared with that of $\mathrm{NO}_{\mathrm{x}}$. It was checked whether the pattern of path-averaged air pollutant concentrations at both sides of the Goettinger Strasse shows the rotorlike circulation inside the street canyon. Whenever possible the data were compared with the results of the wind tunnel that were obtained under carefully controlled and steady boundary conditions. In all cases the data agreed reasonably well with each other and showed the expected qualitative and quantitative behaviour.

From the numerous results obtained only a few can be mentioned here. The analysis of $\mathrm{NO}_{\mathrm{x}}$ concentrations mea- sured at the roof top station during the whole period 20012003 revealed that about one third of the variance of $\mathrm{NO}_{\mathrm{x}}$ concentrations was caused by regional transport and depends on the mixing layer height as shown in Fig. 4 (Schäfer et al., 2005). At ground-level stations this dependence has not been found. The correlation between mixing layer height and $\mathrm{PM}_{10}$ is much weaker and not different for ground and roof top level data, but the $\mathrm{PM}_{10}$ concentrations at ground level inside the street canyon are about twice as high as those at roof level. That confirms the expectation that the concentrations measured at roof top are representative for the urban quarter surrounding the street canyon. In contrast to that, the concentration measurements at ground level are dominated by traffic emissions inside the canyon.

The mixing layer heights for the aforementioned correlation analysis have been derived from the SODAR measurements by analyzing the acoustic backscatter intensity and the standard deviation of the vertical wind component $\left(\sigma_{w}\right)$. This evaluation scheme (Emeis and Türk, 2004) allows distinguishing between super-adiabatic and thermally stable temperature gradients near the surface. The averaged results showed a clear diurnal cycle and an annual cycle of the mixing layer height (Fig. 5). Further, the SODAR data delivered vertical profiles of mean wind speed and turbulence intensity up to $700 \mathrm{~m}$ above ground. Turbulence intensity was especially enhanced at night time due to the larger heat storage at the urban surface (Emeis, 2004).

The comparison of wind vectors determined by the SODAR system with those from the roof top station (10 $\mathrm{m}$ above roof level) showed that for this quantity the roof station measurements are not fully representative for the site. The velocity data are influenced by the building itself and by the building structure surrounding the site. This finding is confirmed 

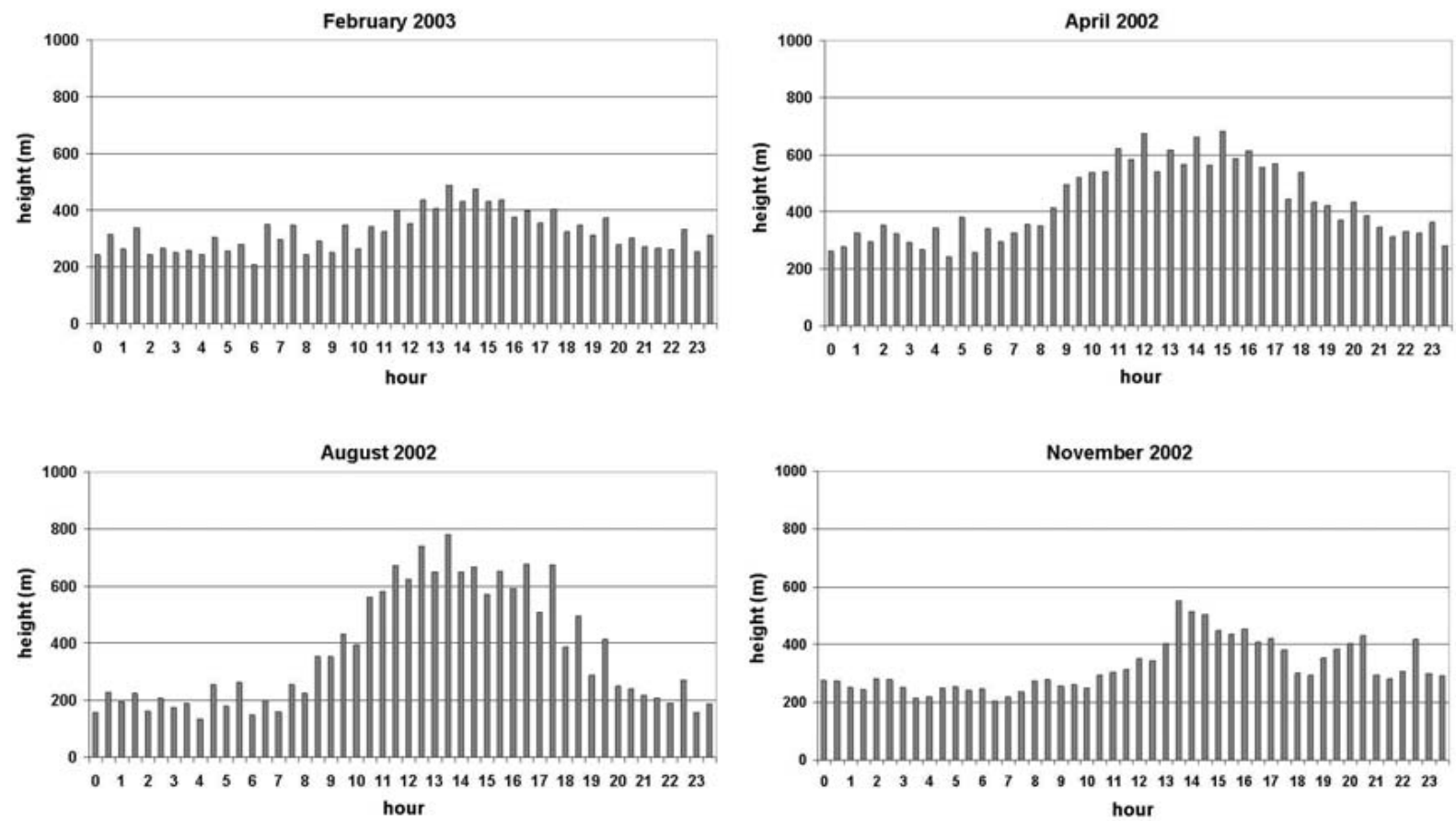

Fig. 5. Monthly mean mixing-layer height over the city of Hanover (Germany) derived from SODAR measurements for four months from the four seasons (from Emeis and Türk, 2004).

by the wind tunnel measurements that allowed quantifying the wind vector modification.

The traffic measurements in the street canyon Goettinger Strasse in Hanover showed, that the driving behaviour and the driving patterns are subject to strong temporal variations. The common procedure to assign a rigid "traffic situation" to a given road segment results in considerable errors and should not be applied in numerical simulations with high temporal resolution. The quality of currently published emission factors (including systematic errors) has been assessed by comparisons between the emission rates, modelled on the basis of the extended traffic measurements, measured pollutant concentrations and the data from the tracer gas experiment (Kühlwein, 2004).

Air pollution in the Goettinger Strasse is predominantly caused by traffic emissions. As is typical for so-called hot spots in cities, the sources and the receptor points are close together. The values measured at the pedestrian walkway must depend on the source location. The VALIUM tracer experiment was carried out with an artificial $\mathrm{SF}_{6}$ line source, which was located at the median strip at the centre of the street canyon, whereas the vehicles emit along the four traffic lanes. To study how the values measured depend on the source conditions, in the wind tunnel (Fig. 6) the following scenarios were carried out, (a) all traffic lanes emitted equally, (b) the lanes emitted according to their traffic density and (c) each lane emitted separately. Since in the field experiments the line source was only $96 \mathrm{~m}$ long, the effect

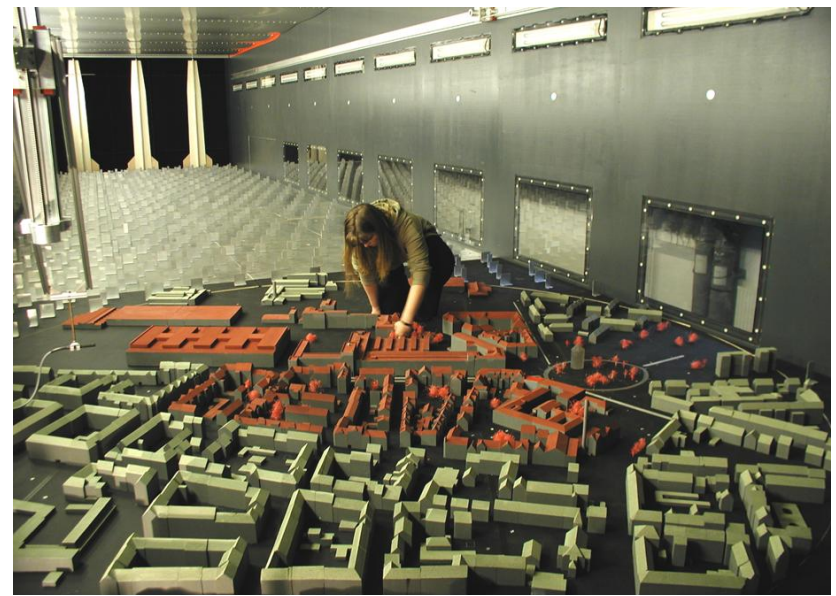

Fig. 6. Physical model of the site in the Boundary Layer Wind Tunnel of Hamburg University.

of the finite length of the source was also studied (Pascheke et al., 2005). Additional laboratory experiments investigated the influence of different averaging times on mean concentration values (Pascheke, $2006^{3}$ ).

\footnotetext{
${ }^{3}$ Pascheke, F.: Systematische Untersuchung von mikroskaligen Strömungs- und Transportprozessen in städtischer Bebauung, $\mathrm{PhD}$ thesis, Dep. of Earth Sciences, University of Hamburg (in German), under preparation, 2006.
} 


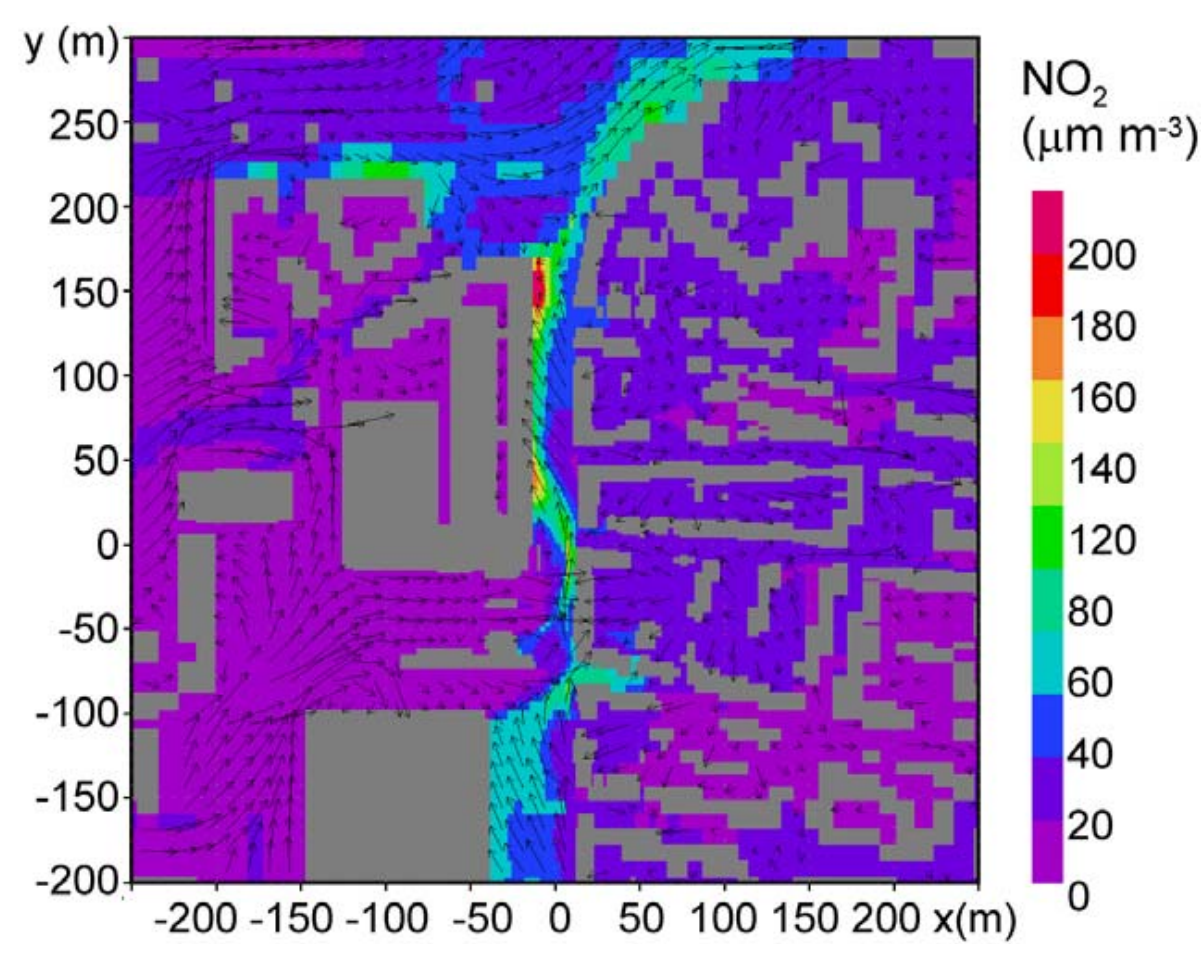

Fig. 7. Numerical model results for the Goettinger Strasse (in the centre of the figure) and vicinity. Shown is a horizontal cross section of $\mathrm{NO}_{2}$ concentration at a height of $1.5 \mathrm{~m}$ above ground for 11 April 2003, 07:00-07:30 as simulated with the MITRAS/MICTM model system. $\mathrm{NO} 2$ is formed by chemical reaction between the primarily emitted $\mathrm{NO}$ and $\mathrm{O}_{3}$ advected into the street from outside. The meandering of the plume in the street canyon is caused by heterogeneities in the wind field. A convergence zone in the northernmost part of the street causes the two peak concentration spots.

During measurement campaigns only individual cases are covered. The characterisation of the general pollutant situation at a site requires numerical modelling. It is known that substantial parts of the pollutant concentrations measured at an urban site can be caused by long-range and regional transport. Therefore it is necessary to apply a hierarchy of meso- and micro-scale models nested into each other. For more than 40 days of year 2000 concentration simulations were performed on a $16 \times 16 \mathrm{~km}$ grid. The selected periods correspond to those situations which have shown high $\mathrm{NO}_{2}$-concentrations in the area of Hanover. The model results were in good agreement with those of the measurements (Schlünzen et al., 2005). Maps showing concentration distributions were compiled at the various scales.

For the VALIUM project the micro-scale flow simulations were of particular interest. Good agreement can be reported between the numerical model results and the data taken within and around the street canyon or in the wind tunnel. The micro-scale concentration fields are very heterogeneous; for westerly flow they show two local peaks some $60 \mathrm{~m}$ apart, which is in agreement with $\mathrm{SF}_{6}$ tracer experiments. For easterly winds it was found that tracers are exported from the street canyon over the roofs into the backyards.
It has been demonstrated that the model system M-SYS is fit for its purpose. M-SYS is presently able to simulate the meteorological fields and the following pollutants considered in the EC daughter directives: $\mathrm{SO}_{2}, \mathrm{NO}_{2}, \mathrm{NO}_{\mathrm{x}}$, some of the $\mathrm{PM}_{10}$-substances (secondary ammonium aerosols), $\mathrm{CO}$ and $\mathrm{O}_{3}$ (Fig. 7). The prototype version of M-SYS is generally available. Due to the fact that the originally planned second period of AFO2000 was cancelled, a fully documented PC version of M-SYS needs still to be developed.

\section{Conclusions}

The combination of field studies, wind tunnel experiments and numerical model simulations within one project proved to be a very successful strategy to investigate the complex flow and transport processes that occur in urban environments. The main objectives of VALIUM, the development of a prototype model system that provides pollutant concentrations in spatial resolutions matched to the requirements of the new European regulations and the generation of a high quality data set based on a combination of field measurements and wind tunnel simulations in a city district, were reached.

Additionally, project VALIUM can give answers to a number of questions that are of particular importance for urban air 
pollution studies:

- How accurate are present emission models for microscale applications?

- What are the chances of ground-based remote sensing techniques for the determination of vertical profiles of atmospheric variables in urban areas?

- What is the influence of surrounding buildings on rooftop measurements at urban sites?

- How much dependent are air pollution levels in urban environments on the height of the mixing layer?

- To which degree are local concentrations influenced by long-range and regional pollutant transport?

- How representative are concentrations measured at positions within the canopy layer with respect to time and space?

- Is the commonly used non-dimensional concentration $c *$ a suitable parameter for the generalisation of street canyon concentrations from one situation to the other?

- To which extent depend numerical or physical model results on the choice of the domain size?

- How sensitive are street canyon measurements to the particular source pattern?

However, there are also open questions for which final answers have not yet been found. These comprise the contribution of vehicle-induced turbulence to pollutant dispersion in street canyons, the representativeness of episodic measurements within the urban canopy layer and the concepts for a unified presentation of concentration data.

Acknowledgement. The authors are grateful for financial support from the German Ministry for Education and Research (BMBF) through the Atmospheric Research Programme AFO2000. Many helpful discussions with the FUMAPEX community are gratefully acknowledged.

Edited by: A. Baklanov

\section{References}

Emeis, S.: Vertical wind profiles over an urban area, Meteorol. Z., 13, 353-359, 2004.

Emeis, S. and Türk, M.: Frequency distributions of the mixing height over an urban area from SODAR data, Meteorol. Z., 13, 361-367, 2004.

Emeis, S., Münkel, Chr., Vogt, S., Müller, W. J., and Schäfer, K.: Atmospheric boundary-layer structure from simultaneous SODAR, RASS, and ceilometer measurements, Atmos. Environ., 38, 273-286, 2004.
Kühlwein, J.: Unsicherheiten bei der rechnerischen Ermittlung von Schadstoff-emissionen des Straßenverkehrs und Anforderungen an zukünftige Modelle, PhD-thesis, Fakultät Maschinenbau, University of Stuttgart (in German), 2004.

Lenz, C.-J., Müller, F., and Schlünzen, K. H.: The sensitivity of mesoscale chemistry transport model results to boundary values, Env. Monitoring and Assessment, 65, 287-298, 2000.

Moussiopoulos, N.: Air Quality in Cities, Springer-Verlag, ISBN 3-540-00842-x, 2003.

Münkel, C., Emeis, S., Müller, W. J., and Schäfer, K.: Aerosol concentration measurements with a lidar ceilometer: results of a one year measurement campaign, in: Remote Sensing of Clouds and the Atmosphere VIII, edited by: Schäfer, K., Comeron, A., Carleer, M., and Picard, R. H., Proceedings of SPIE, Bellingham, WA, USA, Vol. 5235, 486-496, 2004.

Pascheke, F., Leitl, B., and Schatzmann, M.: Dispersion of traffic pollutants in street canyons - a systematic windtunnel study to evaluate a field tracer experiment, Proceedings 5th Int. Conf. on Urban Air Quality, Valencia, March 29-31, 2005.

Rotach, M., Vogt, R., Bernhofer, C., Batchvarova, E., Christen, A., Clappier, A., Feddersen, B., Gryning, S. E., Martucci, G, Mayer, H., Mitev, V., Oke, T. R., Parlow, E., Richner, H., Roth, M., Roulet, Y. A., Ruffieux, D., Salmond, J. A., Schatzmann, M., and Voogt, J. A.: BUBBLE - An urban boundary layer meteorology project, Theor. Appl. Climatol., 81, 231-261, 2005.

Schatzmann, M. and Leitl, B.: Validation and application of obstacle resolving urban dispersion models, Atmos. Environ., 36, 4811-4821, 2002.

Schäfer, K., Emeis, S., Rauch, A., Münkel, Ch., and Vogt, S.: Determination of mixing layer heights from ceilometer data, in: Remote Sensing of Clouds and the Atmosphere IX, edited by: Schäfer, K., Comeron, A., Carleer, M., Picard, R. H., Sifakis, N., Proceedings of SPIE, Bellingham, WA, USA, Vol. 5571, 248259, 2004.

Schäfer, K., Emeis, S., Hoffmann, H., Jahn, C., Müller, W. J., Heits, B., Haase, D., Drunkenmölle, W.-D., Bächlin, W., Schlünzen, H., Leitl, B., Pascheke, F., and Schatzmann, M.: Field measurements within a quarter of a city including a street canyon to produce a validation data set, Int. J. Environ. Poll., 25, 201-216, 2005.

Schlünzen, K. H.: Numerical studies on the inland penetration of sea breeze fronts at a coastline with tidally flooded mudflats, Beitr. Phys. Atmosph., 63, 243-256, 1990.

Schlünzen, K. H., Bohnenstengel, S., and Trukenmueller, A.: Relevance of surface flux aggregation for different meteorological situations, Contribution to EMS Utrecht, 12.-16.09.2005.

Schlünzen, K. H., Hinneburg, D., Knoth, O., Lambrecht, M., Leitl, B., Lopez, S., Lüpkes, C., Panskus, H., Renner, E., Schatzmann, M., Schoenemeyer, T., Trepte, S., and Wolke, R.: Flow and transport in the obstacle layer - First results of the microscale model MITRAS, J. Atmos. Chem., 44, 113-130, 2003.

Schlünzen, K. H. and Katzfey, J. J.: Relevance of sub-grid-scale land-use effects for mesoscale models, Tellus, 55A, 232-246, 2003.

Trukenmüller, A., Grawe, D., and Schlünzen, K. H.: A model system for the assessment of ambient air quality conforming to EC directives, Meteorol. Z., 13, 387-394, 2004. 